Supporting Information

\title{
Flexible Solid-State Supercapacitors with High Areal Performance Enabled by Chlorine-Doped Graphene Films with Commercial-Level Mass Loading
}

Hedong Jiang, Xingke Ye, Yucan Zhu, Ziyu Yue,

Liheng Wang, Jianliang Xie, Zhongquan Wan and Chunyang Jia*

State Key Laboratory of Electronic Thin Films and Integrated Devices, School of

Electronic Science and Engineering, University of Electronic Science and Technology of China, Section 4, North Jianshe Road, Chenghua district, Chengdu 610054, Sichuan province, P. R. China.

*Corresponding author: Email: cyjia@uestc.edu.cn

Number of pages: 13

Number of figures: 10

Number of tables: 2 


\section{Content}

Figure S1. (a) Optical image of Cl-RGOF, (b) Cross-section SEM image of GOF, (c)

Cross-section SEM image of RGOF, (d) Surface SEM image of RGOF S4

Figure S2. $\mathrm{N}_{2}$ adsorption/desorption isothermal curves and PSD plots of (a) GOF. (b)

Cl-RGOF. (c) RGOF

S4

Figure S3. (a) XRD patterns of GOF, RGOF and Cl-RGOF, (b) Raman spectra of

GOF, RGOF and Cl-RGOF

Figure S4. Elemental mapping analysis of $\mathrm{Cl}$ element for $\mathrm{Cl}-\mathrm{RGOF}$

Figure S5. (a) XRD patterns and (b) XPS surveys of RGOFs and Cl-RGOFs prepared by different temperatures S5

Figure S6. (a) CV curves of the Cl-RGOFs tested in two-electrode system. (b) GCD curves of the Cl-RGOFs tested in two-electrode system. (c) The capacitance retention of the Cl-RGOFs. (d) Nyquist plots of the Cl-RGOFs tested in two-electrode system S6

Figure S7. (a) CV curves of RGOF tested in two-electrode system. GCD curves of (b) RGOF and (c) Cl-RGOF tested in two-electrode system. (d) Cycling stability and columbic efficiency of RGOF tested in two-electrode system S7

Figure S8. (a) GCD curves of Cl-RGOF with different mass loadings tested in twoelectrode system. (b) $\mathrm{C}_{\mathrm{a}}$ of $\mathrm{Cl}-\mathrm{RGOF}_{10}$ and $\mathrm{RGOF}_{10}$ at different current densities tested in two-electrode system. S7

Figure S9 (a) CV curves of Cl-RGOF in three-electrode system. (b) CV curves of RGOF in three-electrode system. (c) GCD curves of Cl-RGOF and RGOF at $1 \mathrm{~A} \mathrm{~g}^{-1}$ in three-electrode system. (d) $\mathrm{C}_{\mathrm{M}}$ of $\mathrm{Cl}-\mathrm{RGOF}$ and RGOF at different current densities in 
three-electrode system.

Figure S10 (a) CV curves of Cl-RGOF with different mass loadings at $10 \mathrm{mV} \mathrm{s}^{-1}$ in three-electrode system. (b) GCD curves of Cl-RGOF with different mass loadings at 1 $\mathrm{mA} \mathrm{cm}{ }^{-2}$ in three-electrode system. (c) Relationships of $\mathrm{C}_{\mathrm{G}}$ and $\mathrm{C}_{\mathrm{A}}$ with different mass loadings in three-electrode system. (d) $\mathrm{C}_{\mathrm{A}}$ of Cl-RGOF with different mass loadings at different current densities in three-electrode system. ............................S9

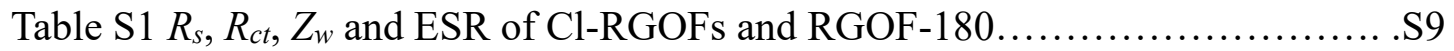

Table S2 Comparison of areal capacitance with recent reports...................S10 

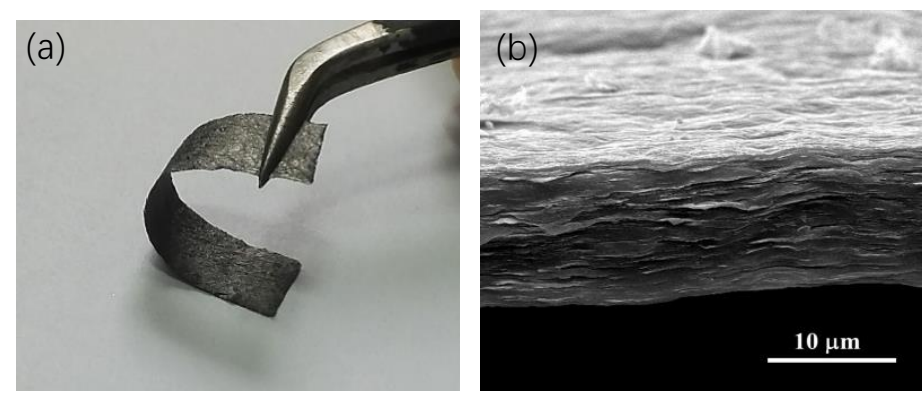

(c)
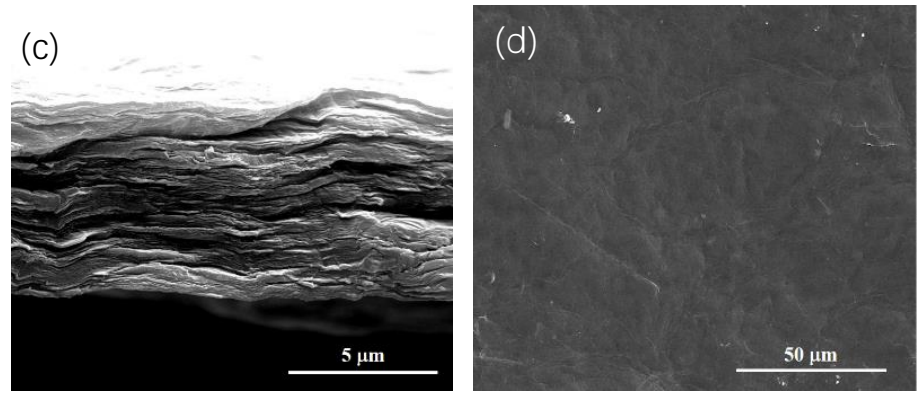

Figure S1. (a) Optical image of Cl-RGOF. (b) Cross-section SEM image of GOF. (c)

Cross-section SEM image of RGOF. (d) Surface SEM image of RGOF.
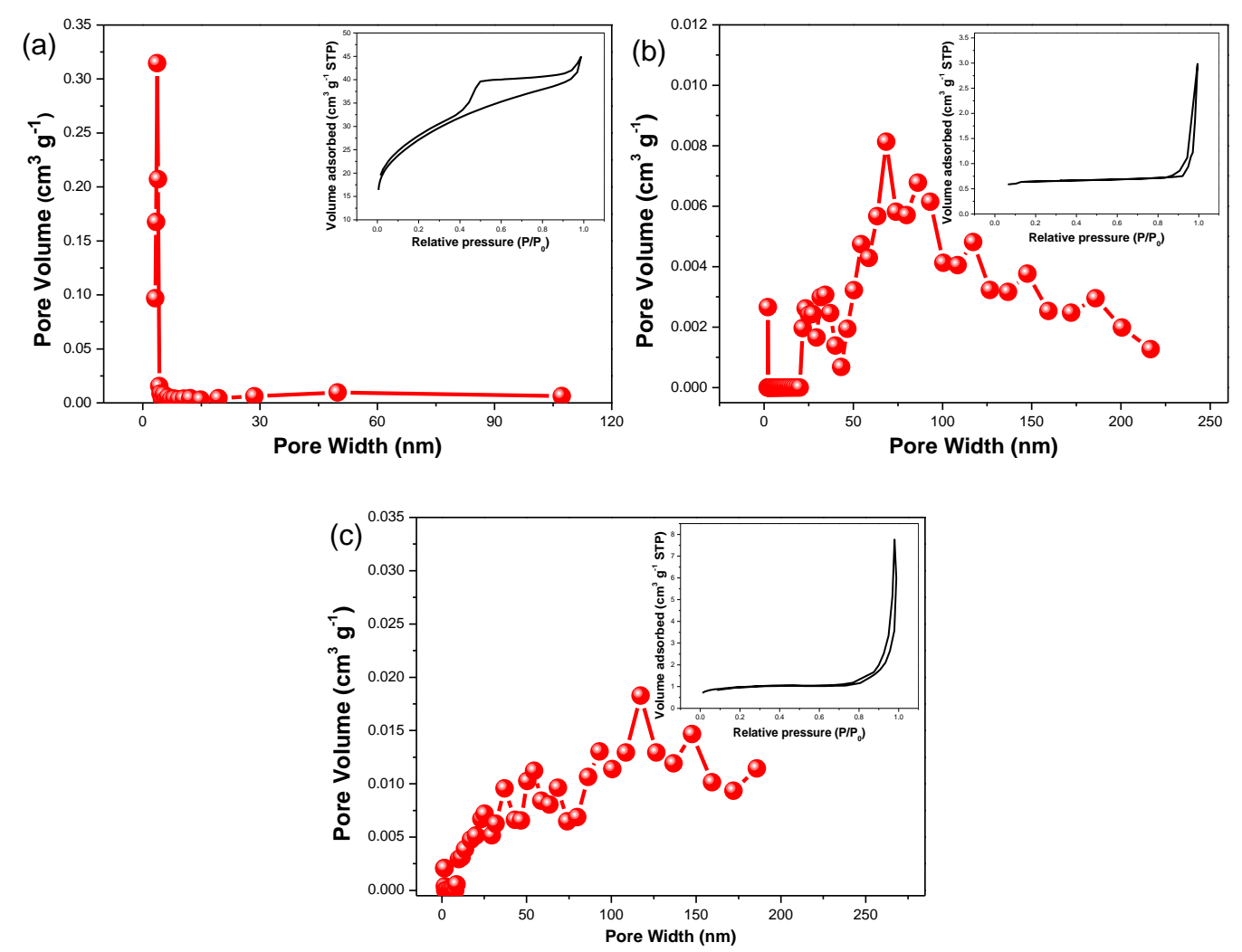

Figure S2. $\mathrm{N}_{2}$ adsorption/desorption isothermal curves and PSD plots of (a) GOF. (b) Cl-RGOF. (c) RGOF. 

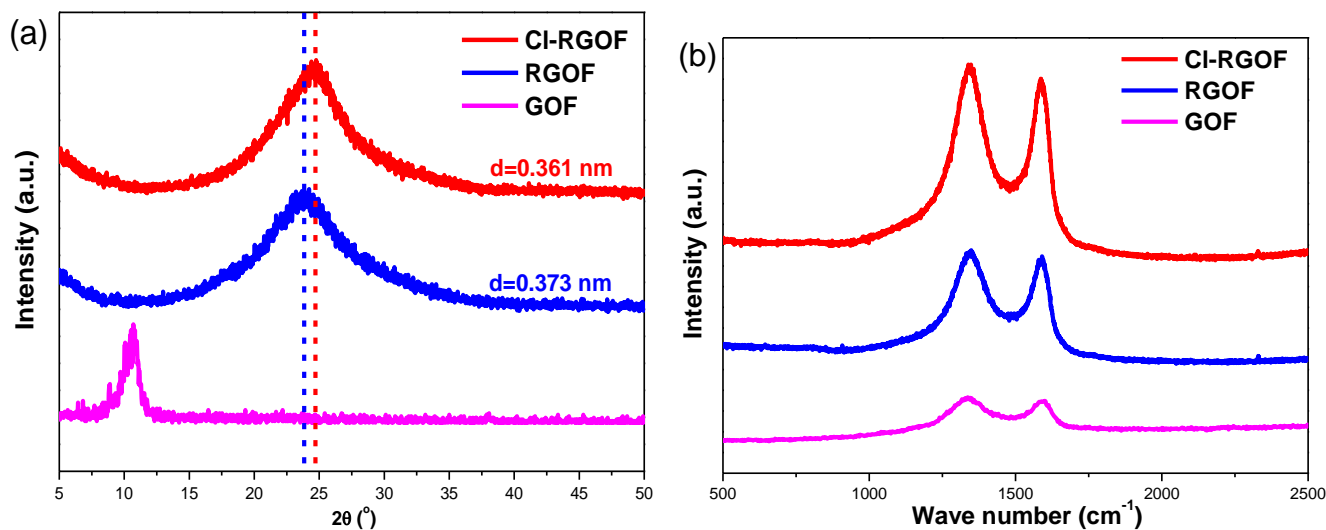

Figure S3. (a) XRD patterns of GOF, RGOF and Cl-RGOF. (b) Raman spectra of GOF, RGOF and Cl-RGOF.

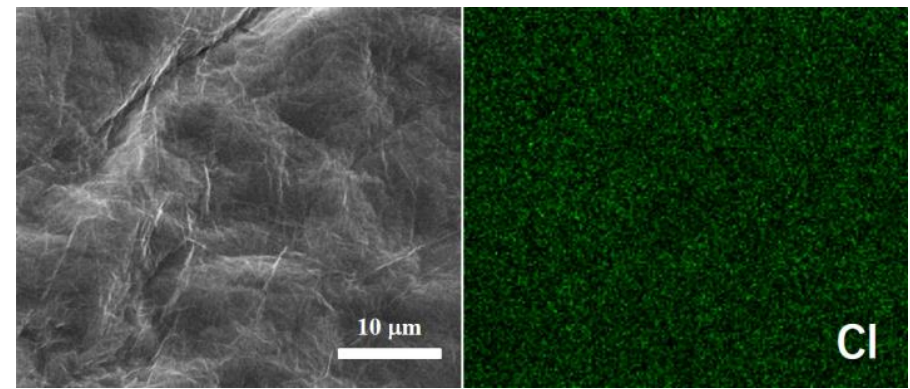

Figure S4. Elemental mapping analysis of $\mathrm{Cl}$ element for Cl-RGOF.
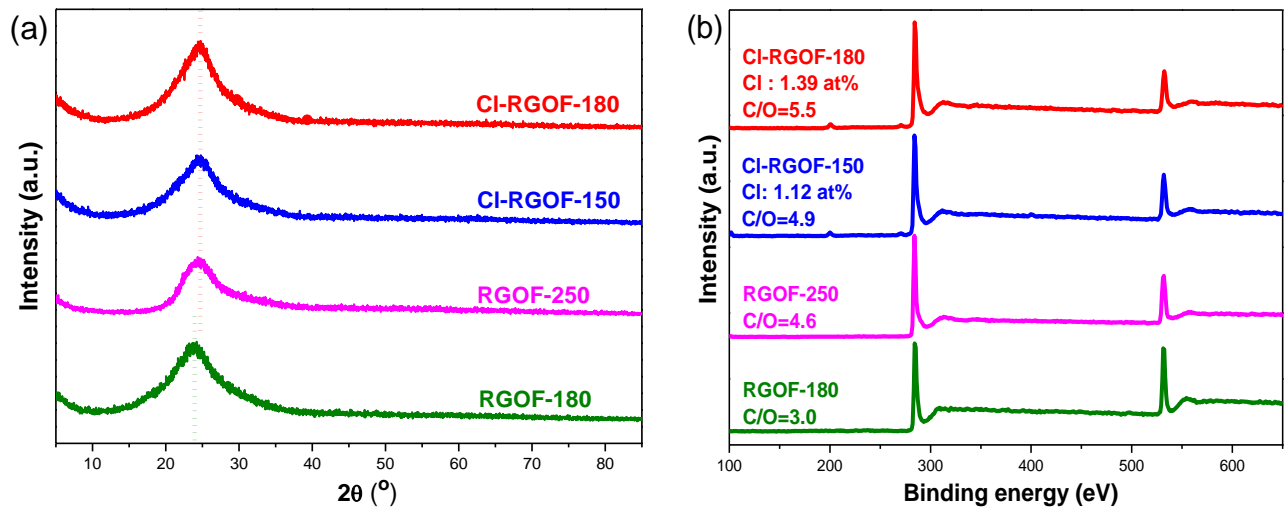

Figure S5. (a) XRD patterns and (b) XPS surveys of RGOFs and Cl-RGOFs prepared by different temperatures. 

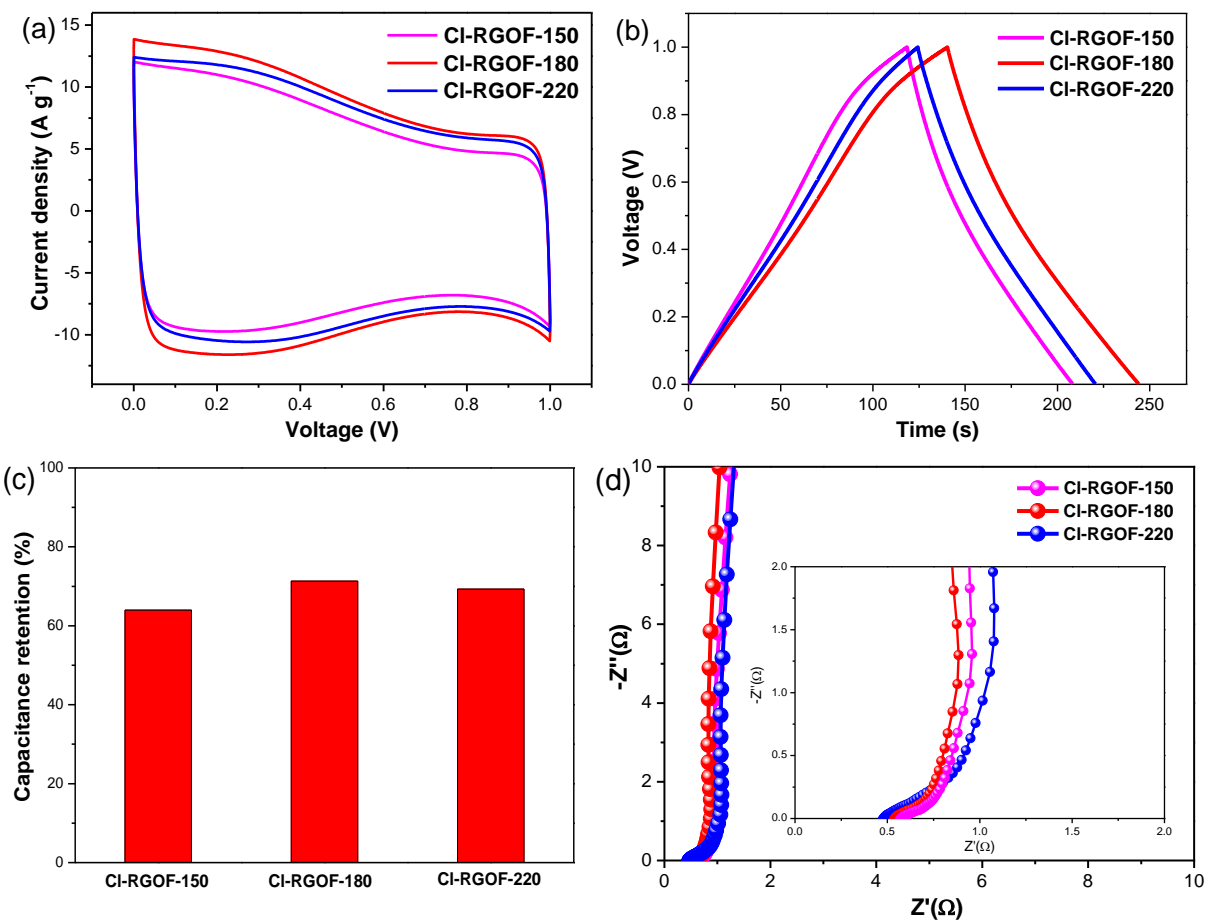

Figure S6. (a) CV curves of the Cl-RGOFs tested in two-electrode system. (b) GCD curves of the Cl-RGOFs tested in two-electrode system. (c) The capacitance retention of the Cl-RGOFs. (d) Nyquist plots of the Cl-RGOFs tested in two-electrode system. 

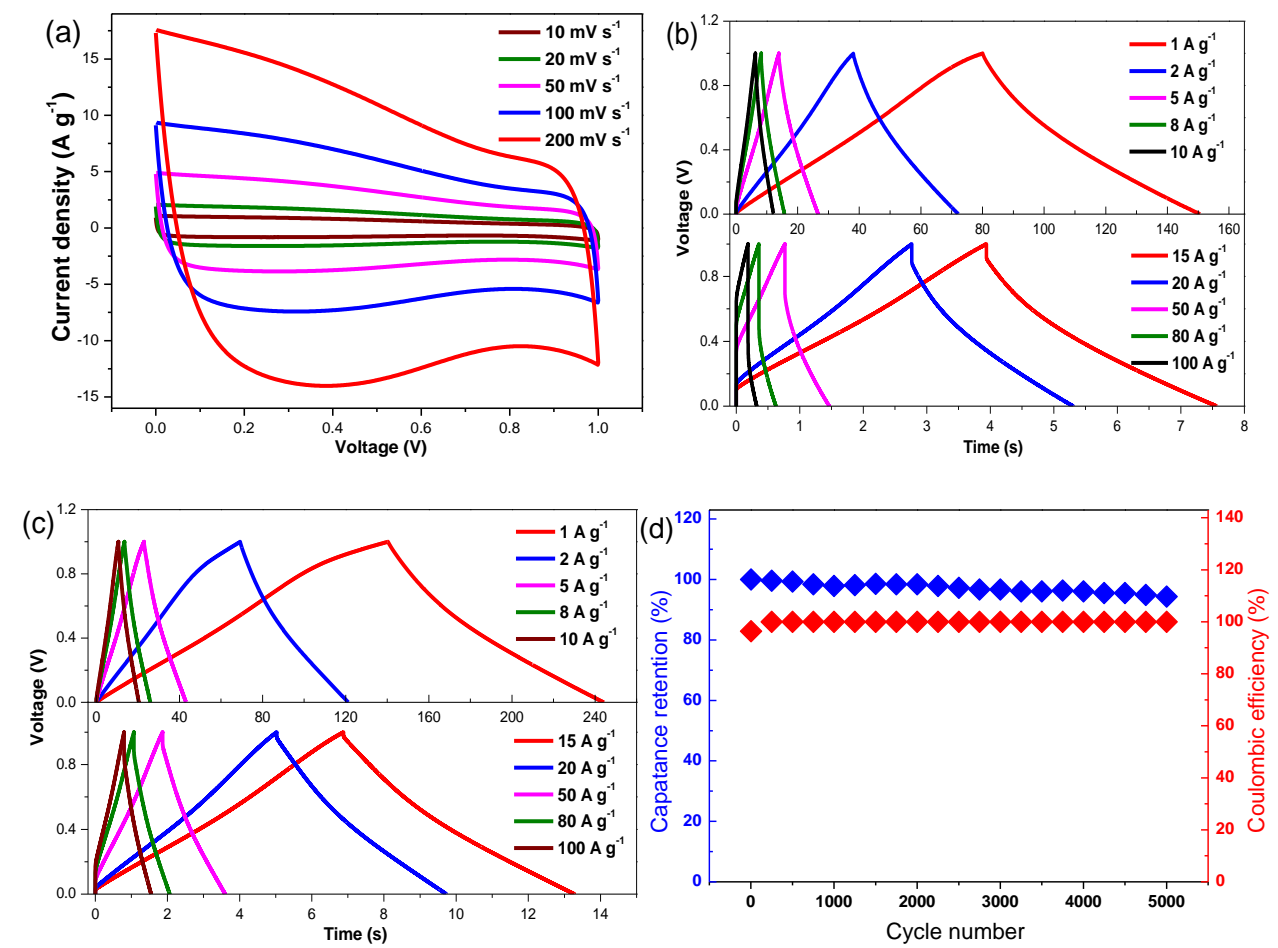

Figure S7. (a) CV curves of RGOF tested in two-electrode system. GCD curves of (b)

RGOF and (c) Cl-RGOF tested in two-electrode system. (d) Cycling stability and columbic efficiency of RGOF tested in two-electrode system.
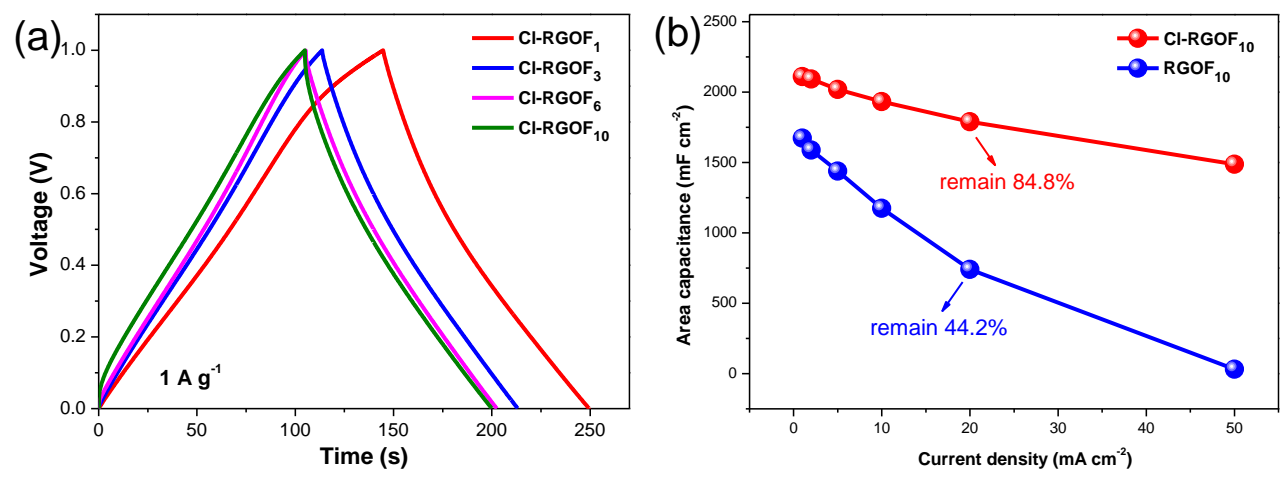

Figure S8. (a) GCD curves of Cl-RGOF with different mass loadings tested in twoelectrode system. (b) $\mathrm{C}_{\mathrm{a}}$ of $\mathrm{Cl}-\mathrm{RGOF}_{10}$ and $\mathrm{RGOF}_{10}$ at different current densities tested in two-electrode system. 

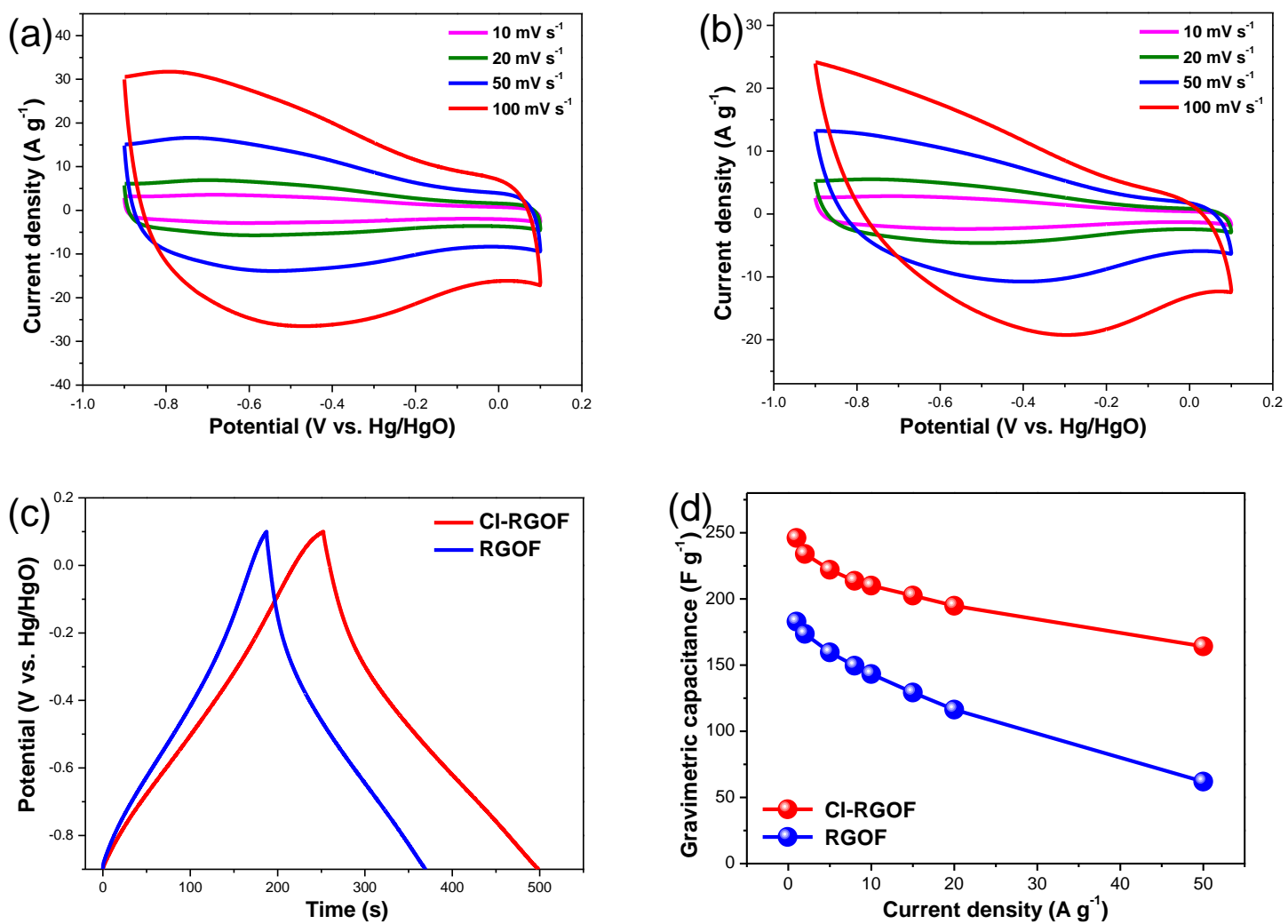

Figure S9 (a) CV curves of Cl-RGOF in three-electrode system. (b) CV curves of RGOF in three-electrode system. (c) GCD curves of Cl-RGOF and RGOF at $1 \mathrm{Ag}^{-1}$ in three-electrode system. (d) $C_{G}$ of Cl-RGOF and RGOF at different current densities in three-electrode system. 

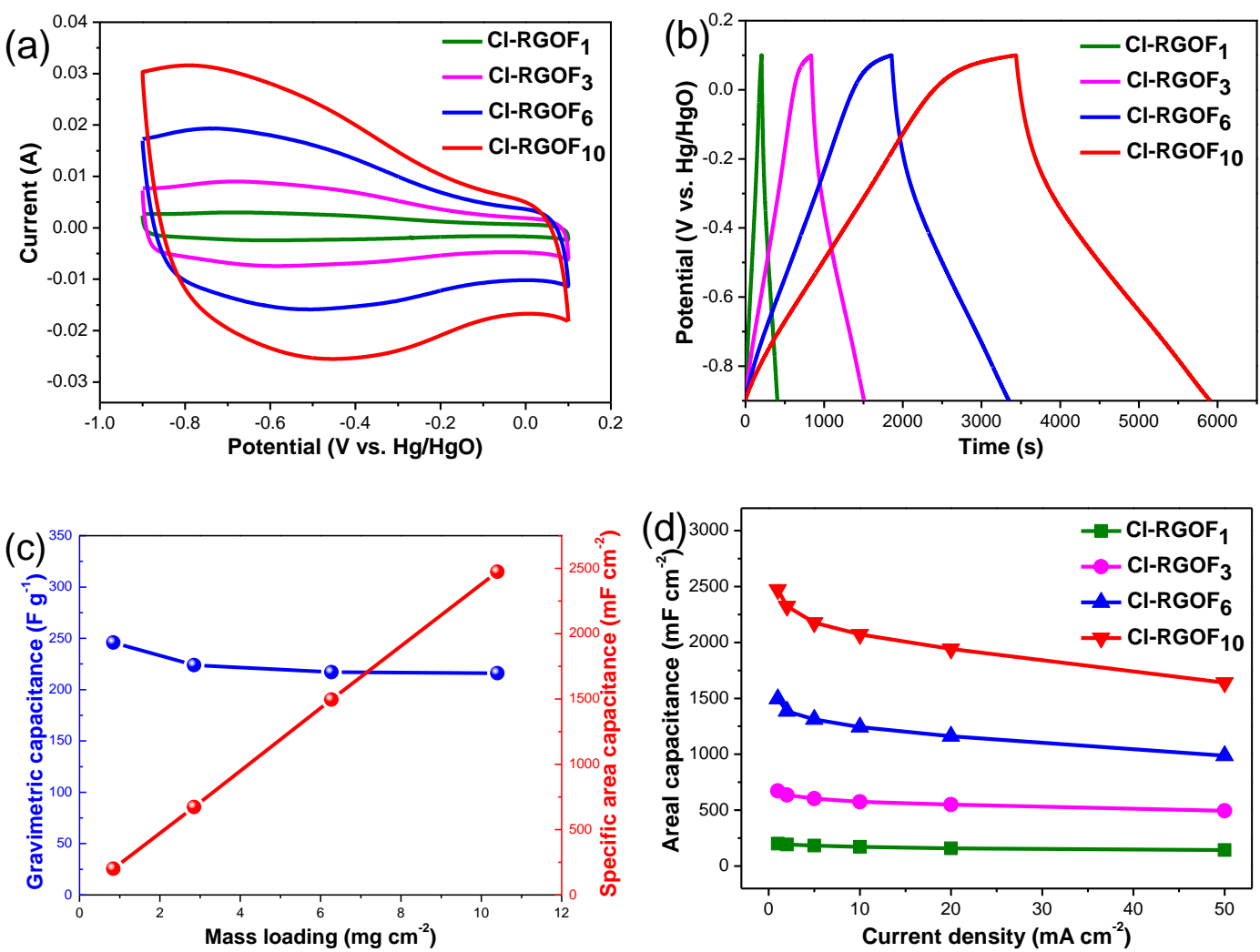

Figure S10 (a) CV curves of Cl-RGOF with different mass loadings at $10 \mathrm{mV} \mathrm{s}^{-1}$ in three-electrode system. (b) GCD curves of Cl-RGOF with different mass loadings at 1 $\mathrm{mA} \mathrm{cm}{ }^{-2}$ in three-electrode system. (c) Relationships of $C_{G}$ and $C_{A}$ with different mass loadings in three-electrode system. (d) $C_{A}$ of Cl-RGOF with different mass loadings at different current densities in three-electrode system.

Table S1 $R_{s}, R_{c t}, Z_{w}$ and ESR of Cl-RGOFs and RGOF-180.

\begin{tabular}{ccccc}
\hline & $R_{s}(\Omega)$ & $R_{c t}(\Omega)$ & $Z_{w}(\Omega)$ & $\operatorname{ESR}(\Omega)$ \\
\hline Cl-RGOF-150 & 0.59 & 0.08 & 0.32 & 0.99 \\
Cl-RGOF-180 & 0.55 & 0.09 & 0.26 & 0.90 \\
Cl-RGOF-220 & 0.51 & 0.17 & 0.45 & 1.13 \\
RGOF-180 & 1.46 & 0.73 & 1.33 & 3.52 \\
\hline
\end{tabular}


Table S2 Comparison of areal capacitance with recent reports.

\begin{tabular}{|c|c|c|c|}
\hline Electrode & $\begin{array}{l}\text { Mass loading } \\
\quad\left(\mathrm{mg} \mathrm{cm}^{-2}\right)\end{array}$ & $\begin{array}{l}\text { Areal capacitance } \\
\qquad\left(\mathrm{mF} \mathrm{cm}^{-2}\right)\end{array}$ & References \\
\hline $\mathrm{Bi}_{2} \mathrm{O}_{3} / \mathrm{CNF}$ & 9 & 545 & 43 \\
\hline $\begin{array}{l}\text { 2D-layered Carbon } \\
\text { metal oxide }\end{array}$ & 13.4 & 2098 & 44 \\
\hline $\mathrm{Ti}_{3} \mathrm{C}_{2} \mathrm{~T}_{\mathrm{x}}$ & 4.8 & 246 & 45 \\
\hline $\begin{array}{c}\text { Hydrolyzed } \\
\text { polyimide/rGO }\end{array}$ & 5 & 1700 & 46 \\
\hline $\begin{array}{l}\text { Activate carbon } \\
\text { cloth }\end{array}$ & 14 & 1137 & 47 \\
\hline Graphite foil & 8.5 & 820 & 48 \\
\hline Graphene paper & 5.3 & 152.4 & 49 \\
\hline $\begin{array}{l}\text { Microporous } \\
\text { graphene }\end{array}$ & 6.4 & 1280 & 50 \\
\hline I-rGO & 6.7 & 524 & 51 \\
\hline $\begin{array}{c}\text { Holey Graphene } \\
\text { Discs }\end{array}$ & 30 & 1300 & 52 \\
\hline 3D Graphene & 11.2 & 1160 & 53 \\
\hline
\end{tabular}


Hierarchical porous graphene

$\mathrm{CuCl}$

Cl-RGOF

\section{Solvothermal temperature impact on electrochemical properties}

Figure S6a shows the CV curves of the Cl-RGOF-150, Cl-RGOF-180 and Cl-RGOF220 (Cl-RGOF-x, where $\mathrm{x}$ represents solvothermal temperature) at $100 \mathrm{mV} \mathrm{s}^{-1}$, showing similar shapes, demonstrating the similar electrochemical properties. Figure S6b exhibits the GCD curves of Cl-RGOFs at $1 \mathrm{~A} \mathrm{~g}^{-1}$, all displaying quasi-rectangular shapes and no IR drops. Figure S6c shows the capacitance retention from $1 \mathrm{~A} \mathrm{~g}^{-1}$ to 100 $\mathrm{A} \mathrm{g}^{-1}$ of the three samples. It can be seen that Cl-RGOF-180 shows a slightly longer discharge span and higher capacitance retention. Nyquist plots of the three sample are also presented in Figure S6d. All the plots show a small semi-circle in high frequency region. Meanwhile, compared with Cl-RGOF-150 and Cl-RGOF-220, Cl-RGOF-180 displays a more vertical line at low frequency region, indicating a better capacitive performance. According to the results, it can be concluded Cl-RGOF-180 possesses slightly better capacitive performance.

\section{Electrochemical measurement for three-electrode configuration}

Three-electrode configuration was set up by using Cl-RGOF or $\mathrm{RGOF}, \mathrm{Hg} / \mathrm{HgO}$ and

platinum foil as working electrode, reference electrode and counter electrode, 
respectively. The CV and GCD were tested in the range of $-0.9 \sim 0.1 \mathrm{~V}$ versus $\mathrm{Hg} / \mathrm{HgO}$.

The $C_{G}\left(\mathrm{~F} \mathrm{~g} \mathrm{~g}^{-1}\right), C_{A}\left(\mathrm{mF} \mathrm{cm}^{-2}\right)$ were calculated by eqs $\mathrm{S} 1$ and $\mathrm{S} 2$, respectively.

$$
C_{G}=\frac{I t}{m \triangle V}(\mathrm{~S} 1) \quad C_{A}=\frac{I t}{S \triangle V}
$$

Where $m(\mathrm{~g})$ and $S\left(\mathrm{~cm}^{2}\right)$ are the active material mass on one electrode and area of one electrode, respectively; $\Delta V(\mathrm{~V})$ is the potential window, $I(\mathrm{~A})$ is the discharge current, $t(\mathrm{~s})$ is the discharge time.

\section{Performance of Cl-RGOFs and GOF measured in three-electrode configuration}

Figure S9a-b displayed the CV curves of Cl-RGOF and RGOF in three-electrode system. Similar as the CV curves tested in symmetrical supercapacitors, all of these curves show combined pseudo-capacitance and electrical double layer capacitance. Furthermore, the enclosed area and current to voltage response are better for Cl-RGOF, which is also consist with the results of tested in symmetrical supercapacitors system, further confirming the excellent performance for Cl-RGOF electrode. From the GCD curves (Figure S9c), it can be obtained that the $C_{G}$ for Cl-RGOF and RGOF are 246 and $182.9 \mathrm{~F} \mathrm{~g}^{-1}$, respectively, which are a little higher than that tested in two-electrode system. From Figure S9d, it can be found that when the current density increased to 50 $\mathrm{Ag}^{-1}$, the $C_{G}$ and $C_{G}$ retention for Cl-RGOF are much higher than those of RGOF, which suggest better rate capability for Cl-RGOF.

Figure S10a shows the $\mathrm{CV}$ of Cl-RGOF with different mass loadings at $10 \mathrm{mV} \mathrm{s}^{-1}$ in three-electrode system. With the increasing mass loading, the CV remain a similar shape, indicating an efficient ion transportation in the film electrodes. From Figure S10b-c, it can be obtained that the $C_{A}$ for Cl-RGOF with $\sim 1,3,6$ and 10 mass loading 
are $200.8,672.5,1496.2$ and $2473.1 \mathrm{mF} \mathrm{cm}^{-2}$, respectively. Besides, the $C_{G}$ for the $\mathrm{Cl}-$ RGOF with $\sim 1,3,6$ and $10 \mathrm{mg} \mathrm{cm}^{-2}$ mass loading are 246, 224, 217 and $216 \mathrm{~F} \mathrm{~g}^{-1}$, respectively. The $C_{A}$ shows a nearly linear growth and the $C_{G}$ remain stable with the increasing of mass loading, which inconsistent with the results tested in symmetrical supercapacitors. From Figure S10d, when the current density increases to a high value of $50 \mathrm{~mA} \mathrm{~cm}^{-2}, C_{A}$ of Cl-RGOF 10 still remains $66.3 \%$, which is $1639 \mathrm{mF} \mathrm{cm}^{-2}$. All these results also indicate $\mathrm{Cl}-\mathrm{RGOF}$ is a promising electrode for supercapacitors. 